\title{
Speculate against Speculative Demand ${ }^{\sqrt{2}}$
}

\author{
O. ap Gwilym ${ }^{\mathrm{a}}$, A. Kita ${ }^{\mathrm{a}}$, Q. Wang ${ }^{\mathrm{a}}$ \\ ${ }^{a}$ Bangor Business School, Hen Goleg, College Road, Bangor LL57 2DG, United Kingdom.
}

\begin{abstract}
We construct a measure of individual investors' speculative demand for stocks from their online queries on penny stocks provided by Google Search volume index (hereafter "SVI"). We examine how such speculative demand relates to the return dynamics of U.S. stock indices. We find that the speculative demand leads to a short-term return reversal. We build a simple trading strategy that sells a stock index when SVI is high and buys the stock index otherwise. It generates annual excess returns of up to $20 \%$ over the buy-and-hold strategy. Applying the trading strategy to the corresponding ETFs and index futures yields similar results. Transaction costs and liquidity risk can partially explain the excess returns. Strong time variation of the excess returns imposes additional limits to arbitrage.
\end{abstract}

Keywords: Investor Attention, Speculative Demand, Penny Stocks, Market Returns, Trading Strategy, Limits to Arbitrage

JEL: G02, G12, G14

\footnotetext{
${ }^{27}$ We thank Dylan C. Thomas for helpful discussions. Errors and omissions remain the responsibility of the authors. Email addresses: owain.apgwilym@bangor.ac.uk (O. ap Gwilym), arben.kita@bangor .ac.uk (A. Kita), q.wang@bangor.ac.uk (Q. Wang)
} 


\section{Introduction}

Individual investors are often perceived to have behavioral biases and trade on noise. If their aggregate demand is random, it should have no predictable and persistent influence on stock prices (Kyle (1985)). However, when their erroneous demand is unpredictable and systematic, noise trade risk limits the arbitrage and enables individual investors to earn higher expected returns than sophisticated investors by bearing more risk (De Long et al. (1990)).

We investigate whether trading against individual investors' speculative demand can create profitable opportunities. We show that a simple trading strategy that sells the U.S. stock index when individual investors' speculative demand is high and holds the stock index otherwise can generate annual excess returns of up to $20 \%$ over the buy-and-hold strategy. This is not a free lunch, however. Transaction costs and liquidity risk can substantially explain the excess returns. Strong time variation of the excess returns imposes additional limits to arbitrage. ${ }^{1}$

We propose a novel measure of individual investors' speculative demand using their online queries on "penny stocks" in Google. We argue for this proxy based on the following reasons. First, penny stocks are speculative. The US Securities and Exchange Commission (SEC) classifies all stocks with prices lower than $\$ 5$ as penny stocks. As a typical example of speculative stocks, ${ }^{2}$ penny stocks have highly volatile prices, are difficult to analyze and very risky, which creates space for differences of opinion and speculative trading. Existing literature establishes that penny stocks tend to be overpriced. ${ }^{3}$ Second, we propose that individual investors are more likely to use Google to search for information for trading, which is consistent with the findings of Da et al. (2012). Third, the search intensity on "penny stocks" reflects individual investors' net demand for speculative stocks. An individual investor often faces a formidable search problem: among thousands of stocks, upon which one(s) should he speculate? This problem is more severe when buying than selling stocks (Barber and Odean (2008)), implying that search activities are more likely to be related to buying interest. In contrast, institutional investors hold much larger stock portfolios and hence face a search problem when selling stocks too. This is the case especially when they want to short sell, since they need to search for which stocks to short sell. Barber and Odean (2008) test and confirm the hypothesis that individual investors are net buyers of attention grabbing stocks. Therefore the Google search volume index

\footnotetext{
${ }^{1}$ By an arbitrage we do not imply a truly riskless arbitrage in a textbook sense. In fact, our trading strategy is a risky strategy that can incur losses in some periods.

${ }^{2}$ Penny stocks are widely perceived as speculative securities among economic and legal researchers (e.g., Aggarwal and Rivoli (1990), Beatty and Kadiyala (2003) and Bouraoui (2011)), financial regulators (http://www.sec.gov/answers/penny.htm), financial media (McLean (2000)) and financial professionals (see, for example, http://www.investopedia.com/terms/s/speculativestock.asp)

${ }^{3}$ For example, Beatty and Kadiyala (2003) and Bradley et al. (2006) show that penny stock IPOs have higher initial returns but significantly worse long-run underperformance than ordinary IPOs. Hanke and Hauser (2008) report that the portfolio of penny stocks lose almost $90 \%$ over a year, while the Russell Microcap Index gained $2.57 \%$ during the same period.
} 
of "penny stocks" should reflect retail investors' speculative demand. ${ }^{4}$ Note that we do not study penny stocks per se. Instead, we use the interest in penny stocks search in Google as a measure of the general public's willingness to speculate in the stock market.

Measuring the speculative demand by SVI adds our paper to a growing body of literature on the role of investor attention/information demand measured on asset markets. In an information abundant environment such as financial markets, attention constrained investors have to allocate attention across different assets before portfolio selection. Recent theoretical studies show that limited attention affects asset price dynamics such as stock market volatility (Andrei and Hasler (2011)), return comovement, and return predictability (Peng and Xiong (2006)). Empirically testing the theory of attention calls for a proxy of investor attention. Traditional measures include media coverage, extreme price movement, or advertising expense. Unlike these indirect proxies of investors' passive attention, Da et al. (2012) propose a direct measure of investors' active attention: the search intensity on certain assets through Google. Since their seminal paper, a growing literature revisits the relationship between investors attention and asset prices. ${ }^{5}$ This literature examines the effect of search on either individual stocks or stock indices. Unlike them, we restrict our attention to penny stocks only.

Using our novel proxy of investors' speculative demand, we test how it relates to the returns on U.S. stock indices. From in-sample regressions, we find that contemporaneous returns increase with Google Search Volume Index (SVI) of penny stocks search volume. In addition, higher SVI causes lower near future returns, while recent high past returns cause lower SVI. We also find that the influence of speculative demand on returns is more pronounced for Nasdaq than DJIA and S\&P 500. These results are consistent with the "theory of attention" in Barber and Odean (2008): when the speculative demand is high, 1) contemporaneous returns are high due to high buying pressure, which drives up current price and returns; 2) future returns are lower. The rise of the current price is short lived (only temporary). When the mispricing is corrected, future returns decline as the price falls; 3) the search interest in penny stocks plays a stronger role for returns of Nasdaq than DJIA and S\&P 500, since securities listed on Nasdaq are smaller and less liquid, which makes it more difficult for sophisticated investors to correct the mispricing.

Based on the in-sample short term return reversal, we build a simple trading strategy that sells a stock index when SVI is high and buys the stock index otherwise. It generates an annual excess return of up to $20 \%$ over the buy-and-hold strategy. Accounting for transaction costs lowers the excess returns. Liquidity

\footnotetext{
${ }^{4}$ Although not reported in the paper, we consider alternative measures of speculative demand by using more general search keywords such as "best stocks", "buy stocks", "hot stocks", "stock picks", "stocks to buy" and "top stocks". We find similar empirical evidence.

${ }^{5}$ This strand of literature examines the usefulness of Google search volume index in explaining asset market phenomena such as stock prices around earnings announcements (Drake et al. (2011)), liquidity and returns (Bank et al. (2011)), predicting a firm's future cash flow (Da et al. (2010)), biased attention towards local stocks (Mondria and Wu (2012)), and stock market volatilities (Vlastakis and Markellos (2012)).
} 
risk can also partially explain the excess returns since the strategy performs well mainly during periods of high liquidity risk. In addition, there is strong time variation in the excess returns. Therefore we conclude that the substantial excess returns to the trading strategy do not necessarily imply profitable opportunities.

It might appear unclear what "buying/selling" an index means. We therefore examine not only market indices but also their corresponding Exchange Traded Funds (ETFs). Investing an ETF that tracks an index, one can get the diversification of an index fund as well as the ability to sell short. ETF can be traded like stocks, and the transaction cost is usually low. We adjust our simple trading strategy to sell an ETF when SVI is high and to buy and hold it otherwise. We find similar results as "trading" the index itself.

We also examine the performance of our trading strategy using price data on the index futures. Trading futures contracts incurs quite modest transaction cost. In addition, taking short positions using the futures is more realistic than using the index itself. We find similar results based on trading index futures.

Our trading strategy relies on the short term reversal of market returns conditional on individual investors' speculative demand. It relates our paper to a large literature on short term momentum and long term reversal. ${ }^{6}$ The approach in such literature tends to involve portfolios of winners and losers conditional on the individual asset's past performance. In a recent theoretical paper, Nagel (2012) shows how returns of short-term reversal strategies in equity markets can be interpreted as a proxy for the returns from liquidity provision. In this model, the public trades for informational and liquidity reasons, while the market makers have limited risk bearing capacity, and the author shows that reversal strategies closely track the returns earned by liquidity providers. The buying and selling in reversal strategies mimics the trading of a market maker who sells when the public buys and buys when the public sells, which coincides with rising and falling prices respectively.

The buying/selling decisions of our unique short-term reversal strategy is based on whether the increase in the informational speculative demand level of individual investors is substantially higher than its historical online search level. This approach is distinctive from the previous papers in the literature on short term momentum and long term reversal which base their trading strategies on the assets' past performance. In the spirit of Nagel (2012) it follows that our trading strategy effectively resembles the trading of a market maker (liquidity provider) that sells when the public buys and buys otherwise. The informational source for our trading strategy is however based on a unique feature, which is the level of the public's informational demand for speculation, as opposed to the assets' historical performance. Our trading strategy sells when the speculative demand is high and buys when the speculative demand is low. In addition, we examine its impact on market returns, not the returns of a managed portfolio. Moreover, our strategy exploits the conditional

\footnotetext{
${ }^{6}$ See for example, Cutler et al. (1991), Jegadeesh and Titman (1993), Rouwenhorst (1998), Rouwenhorst (1999) and Levis and Liodakis (2001) among others.
} 
short-term return reversal, instead of short term momentum or long term reversal.

The remainder of the paper is organized as follows. Section 2 describes and summarizes our data set. Our in-sample empirical results are provided in Section 3, and Section 4 discusses the trading strategy. Section 5 concludes. We provide some additional results in the Appendix.

\section{Data}

\subsection{Search Volume Index}

Google trends provides SVI computed as the portion of worldwide Google web search on certain keywords over a certain period relative to the total number of searches using Google during that period. These numbers are firstly normalized and then scaled from 0 to 100 in order to make them comparable across regions. We download weekly data spanning from 10/01/2004 to 14/04/2012 for a total of 432 weekly observations.

The phrase we use in Google Insights is "penny stocks". It reflects investors' interest in speculative stocks. "Level of SVI" is the original search volume index. We consider two measures of investors' speculative demand based on the SVI. The first one is "Change in SVI", the weekly change in the search volume index. The second measure is "SVI Innovation". It is obtained as the residual from a linear regression of the original search volume index on its own first lag, a constant and monthly dummies in order to remove the persistence and seasonality of the original series. In the empirical analysis we report our results for both measures.

Table 1 contains the summary statistics of our speculative demand variables. It shows that they have substantial time variation and leptokurtosis.

[Insert Table 1 about here]

One important question relating to our speculative demand variables is whether they have unit roots. For that purpose we conduct three unit root tests without a trend component: the Augmented Dickey-Fuller test, the Phillips-Perron test, and the Dickey-Fuller-GLS test. The Dickey-Fuller-GLS test performs a modified Dickey-Fuller $t$ test for a unit root in which the series has been transformed by a generalized least-squares regression. All tests reject the existence of a unit root at the $1 \%$ level for both measures of speculative demand.These results are available upon request. 


\subsection{Descriptive Statistics of Weekly Returns}

We collect data on stock indices from Bloomberg. The sample period is the same as for the speculative demand variables. We report the descriptive statistics of weekly returns in Table 2. It shows that returns display high volatility, negative skewness and excess kurtosis during our sample period.

[Insert Table 2 about here]

\section{In-sample Results}

\section{A First Look at Returns and Speculative Demand}

We take a first look at the relationship between individual investors' speculative demand and the stock index returns by documenting the average returns in high and low speculative periods. High (low) speculative demand periods refer to the periods during which the speculative demand is higher (lower) than the median speculative demand in the whole sample. Table 3 reports the results for both speculative demand measures. It shows that the average weekly returns are negative in low speculative demand periods, and positive in high speculative demand periods. The differences in returns of these two periods are economically significant. For example, when speculative demand is measured by change in SVI, DJIA has an average weekly return of $-0.23 \%$ in low speculative demand periods and $0.32 \%$ in high speculative demand periods. The spread is $0.55 \%$ per week, corresponding to an annualized spread of $28.6 \%$. The spreads are even larger for S\&P 500 and Nasdaq.

[Insert Table 3 about here]

\section{Contemporaneous Regressions}

To investigate how much of the variation in the weekly returns can be explained by the contemporaneous speculative demand alone, we regress returns on the measures of speculative demand in addition to a constant. Table 4 shows that the coefficients of speculative demand are positive and significant at the $1 \%$ level for both measures of speculative demand and across different market indices. Despite the significance of the coefficients, the adjusted $R^{2}$ is small. Still, the economic significance of speculative demand for returns is high, since a one unit change in speculative demand is related to about $0.05 \%$ change in weekly returns, which corresponds to an annualized return of $2.6 \%$. The size of the coefficient of speculative demand also 
suggests that the role of speculative demand on returns is more pronounced for Nasdaq than DJIA and S\&P 500 .

[Insert Table 4 about here]

The above OLS regression does not consider the GARCH effect in weekly returns. We therefore augment a GARCH(1,1) model with measures of investor speculative demand by allowing it to enter both specifications of the conditional mean and conditional variance. We refer to this model as "SVI-GARCH(1,1)"

$$
\begin{aligned}
r_{t} & =\alpha+\beta S V I_{t}+\epsilon_{t} \\
\sigma_{t}^{2} & =\exp \left(\lambda_{0}+\lambda_{1} S V I_{t}\right)+\gamma \sigma_{t-1}^{2}+\delta \epsilon_{t-1}^{2}
\end{aligned}
$$

where $\epsilon_{t}=\sigma_{t} z_{t}$ and $z_{t} \stackrel{\text { iid }}{\sim} N(0,1) . \lambda_{1}$ is the coefficient for the attention variable in the conditional variance equation, $\gamma$ is the coefficient of the GARCH term $\sigma^{2}$ and $\delta$ is the coefficient of the ARCH term $\epsilon^{2}$. "SVI" refers to our measures of the speculative demand.

Table 5 shows that the speculative demand is strongly and positively related to contemporaneous returns after GARCH effects have been taken into account. The coefficients are marginally smaller than those in Table 4. In addition, speculative demand does not have a robust relationship with the conditional volatility of market returns.

[Insert Table 5 about here]

Adding moments of past returns and macroeconomic variables as additional regressors does not change the role of speculative demand. We consider the first four moments of daily returns in the past 30 days, the U.S. three month Treasury bill rate, change in consumer confidence index (CCI), change in industrial production, change in consumer price index (CPI), and change in money supply (M2). ${ }^{7}$ Table 6 shows that both the statistical and economic significance of the coefficients on the speculative demand are similar to those in Table 4.

\section{[Insert Table 6 about here]}

\footnotetext{
${ }^{7}$ These macroeconomic variables are downloaded from Datastream. They are all at monthly frequency. We lag these variables by one month to avoid endogeneity issues.
} 
Another robustness check we apply is to examine the effect of outliers and nonlinearities. We run median regressions for the same model specifications and find similar results. ${ }^{8}$

\section{VAR and Causality}

Although we find that the speculative demand is significantly related to contemporaneous returns, this finding is open to the possibility that both variables can be jointly determined. In addition, it cannot answer the question on causal effects between these variables. It can well be that an increase in returns inspires investors which then triggers their speculative demand (thus raising their subsequent speculative demand).

We run Vector Auto Regressions (VAR) to examine this question. Specifically, we estimate a VAR(2) model with the following specification:

$$
\begin{aligned}
\operatorname{SVI}_{t} & =\beta_{0}+\beta_{1} \operatorname{Return}_{t-1}+\beta_{2} \operatorname{Return}_{t-2}++\beta_{3} \mathrm{SVI}_{t-1}+\beta_{4} \mathrm{SVI}_{t-2}+\eta_{1, t} \\
\operatorname{Return}_{t} & =\lambda_{0}+\lambda_{1} \mathrm{SVI}_{t-1}+\lambda_{2} \mathrm{SVI}_{t-2}++\lambda_{3} \operatorname{Return}_{t-1}+\lambda_{4} \operatorname{Return}_{t-2}+\eta_{2, t}
\end{aligned}
$$

[Insert Table 7 about here]

Table 7 reports the results. Across all stock indices the first lag of the speculative demand measure is significantly negative at least at the $5 \%$ level. In addition, the absolute size of the coefficients on speculative demand is higher for Nasdaq than DJIA and S\&P 500. We also find that the coefficients of the first lag of returns are positive at the $10 \%$ level.

A natural question is whether the causal relation of the speculative demand with respect to contemporaneous returns holds when other control variables are included in the VAR specification. Although not reported, inclusion of the moments of past returns and macroeconomic variables, or adding further lags into the VAR system, does not change the link between speculative demand and returns.

\section{A Simple Trading Strategy}

The empirical implementation of our short-term reversal strategy requires some adjustments to account for the complexities that theoretical models of reversal strategies abstract from for the sake of clear intuition. We now discuss the choices we adopt in our empirical implementation of the reversal strategy.

\footnotetext{
${ }^{8}$ Results are available upon request from the authors.
} 


\section{Individual stocks or indices}

The mainstream approach of analysing reversal strategies employs portfolios of individual stocks. As the liquidity explains part of the profitability, basing our trading strategy on indices rather than individual stocks makes our results likely to be conservative. Higher profits are expected for portfolios composed of less liquid stocks (e.g. small or distressed stocks). In addition, index returns reflect price pressure shocks that affect the entire market. This bodes well for our approach of using the general public's search for penny stocks in Google for the short-term reversal strategy.

\section{Return measurement horizon}

Using NYSE data Hendershott and Menkveld (2012) find half-lives ranging from a half-day for largest stocks to two days for the smallest stocks. Considering that penny stocks are the smallest stocks in the market, while our trading strategy is based on the search volume for such stocks, our data captures much of the effects of imperfect liquidity provision. On the other hand Wang (1994) and Llorente et al. (2002) show that long-lived private information can induce positive serial correlation at short horizons. It follows that conditioning the reversal strategy for day $t$ on day $t-1$ speculative demand might play down the returns from supplying liquidity. We calculate the returns of our reversal strategy conditioned on $t-5$ days of speculative demand.

\section{Transaction prices}

We base our reversal strategy on closing transaction prices which represent the returns of a hypothetical representative liquidity supplier whose limit orders or quotes are always executed at the closing transaction prices.

\section{Sample period}

Khandani and Lo (2007) report that returns of a similar reversal strategy during the "quant crisis" in August 2007 delivered substantial losses, however transitory, over a period of few days. Our dataset spans over a relatively long time period thus allows us to study the time variation in excess returns from short-term reversal (liquidity provision), particularly during the financial crisis of 2007-2009. The results of our trading strategy (as explained in the following subsection) show that our trading strategy was highly profitable during the subsequent financial crisis period.

\section{The setup of the trading strategy}

Based on the results of short-term reversals in weekly returns following a rise in individual investors' speculative demand as reported in Table 7, we propose a simple trading strategy that sells a stock index 
when individual investors' speculative demand (SVI) is high and buys the stock index when the speculative demand is low. Since the historical data of SVI are known at the end of a week, we assume that investors who apply this trading strategy will take positions at the closing price index next Monday. Although trading strategies have been frequently applied to stock indices in the literature (e.g., Sullivan et al. (1999)), it might appear unclear what "buying/selling" an index means for an investor. Therefore, we examine the Exchange Traded Funds (ETFs) that track an index in a later section. In this section we first report the performance of this trading strategy, we then discuss the effect of outliers on excess returns, followed by some discussion on alternative specifications of trading strategies. We consider different possible limits to arbitrage, including the time-variation of this strategy, effects of transaction cost and liquidity risk.

\subsection{Performance of the Trading Strategy}

Our baseline implementation of the strategy sells a stock index at time $t$ when the SVI is above the 75th percentile of its historical values of our sample up to the time $t$ and buys and holds the stock index otherwise. The cut-off point at the 75th percentile is arguably arbitrary. Instead, a cut-off point at the median (50\%) might appear more natural. Unfortunately, this will lead to an excessive number of trades which can incur large transaction costs. On the other hand, a cut-off point close to $100 \%$ will leave little room for the trading strategy to perform differently from the buy-and-hold strategy. Our choice of 75th percentile is a result of balancing these tradeoffs. We consider other cut-off points when discussing alternative specifications of trading strategies below.

Since we need to find the 75th percentile of the historical values of SVI, we use the first 50 weeks' data to initialize our trading strategy. We calculate excess returns which are defined as the returns to our trading strategy over the buy-and-hold strategy, a natural benchmark for assessing the profitability of a trading strategy in equity markets. We first assume no transaction costs, and leave the detailed discussion of transaction costs to the subsequent section.

Panel A of Table 8 reports the summary statistics of the excess returns for all three indexes. The average weekly excess returns of our trading strategy is $0.34 \%$ for DJIA, $0.42 \%$ for the S\&P 500 and $0.46 \%$ for Nasdaq. These correspond to annualized implied excess returns of $17.68 \%$ for DJIA, $21.84 \%$ for S\&P 500 and $23.92 \%$ for Nasdaq.

The high excess returns are also accompanied by relatively low standard deviations. This is also reflected in very high Sharpe ratios $(0.13$ to 0.15$)$ of reversal strategy adopted in this paper as reported in the last column of Table 8 .

Interestingly, Table 8 reports large positive skewness of the excess returns, which is in contrast to the negative skewness in market returns in Table 2. Negative skewness is often taken as a measure of crash 
risk. Therefore, it appearers that the exposure to asymmetric downside risk can be ruled out as a possible explanation of the high Sharpe ratios. The pronounced positive skewness in excess returns indicates a propensity of our trading strategy to generate large positive returns with greater probability.

In the penultimate column of Table 8, we report the relative frequency of positive returns versus negative returns. For each stock index, the excess returns are more likely to be positive than negative. In particular, about 70\% (30\%) of excess returns are positive (negative) for DJIA. The last column reports the Sharpe ratio of the trading strategy, which is defined as the mean of excess returns over the buy and hold divided by their standard deviation. For all three indices, the trading strategy has a weekly Sharpe ratio of about $15 \%$. Finally, the excess returns display large kurtosis. In sum, the high excess returns of our trading strategy accompanied by relatively low standard deviations and high Sharpe ratios indicate that the volatility of returns from the reversal strategy by itself is an implausible cause of impediment that dissuades investors from investing in this type of strategy.

Of course there are many other institutional and market microstructure effects which can prevent more aggressive entry into the liquidity provision business that would lower the Sharpe ratios reported in Table 8. We discuss some of these impediments below.

[Insert Table 8 about here]

What can explain the large excess returns? A potential set of determinants include the moments of past returns and macroeconomic variables. To check this, we regress excess returns on these variables. We consider two model specifications. In the first model we consider only the moments of excess returns as regressors. In the second model we add the macroeconomic variables. Table 9 reports the results. Almost none of these variables can explain the excess returns. The only exception is the lagged change in consumer confidence index. Consumer confidence index is often taken as a measure of investor sentiment. There is a large literature showing a significant relationship between investor sentiment and stock returns (e.g., Baker and Wurgler (2006) and Fisher and Statman (2000)). Our result indicates that excess returns are related to the change in the investor sentiment. Other factors such as the transaction costs and the liquidity might be more important determinants of excess returns. We discuss them in depth below.

[Insert Table 9 about here] 


\section{The Effects of Outliers}

The distributional properties of the excess returns presented in Table 8 call for more careful analysis of the effect of outliers on the profitability of our trading strategy. Thus, we winsorize the highest and lowest $1 \%$ excess returns. Table 10 reports the results of the strategy after the extreme returns are excluded. The excess returns decline substantially. For example, the weekly excess returns to DJIA is reduced from $0.34 \%$ to $0.23 \%$ when outliers are removed. Despite that, excess returns are still positive and economically large. The annualized excess returns are $11.96 \%$ for DJIA, 14.56\% for S\&P 500 and $16.64 \%$ for Nasdaq. In addition, there is little change in the weekly Sharpe ratio when the outliers are removed. That is, a few outliers in excess returns contribute only partially to the performance of the trading strategy.

[Insert Table 10 about here]

\section{Alternative trading strategies}

To investigate the robustness of our trading strategy to different cut-off points, we consider two additional cut-off points: 90th percentile and one standard deviation of historical speculative demand up to time $t$. Table 11 reports the summary statistics of excess returns when the 90th percentile cut-off is applied. We obtain lower average excess returns than those in Table 8 , with a decline of about $40 \%$ compared to the case of 75th percentile cut-off point. As expected, there is a substantial decline in the number of executed trades (46 versus 142). This will reduce the negative effect of transaction costs on the profitability of the trading strategy. Yet trading less frequently may miss some profitable trading opportunity. The weekly Sharpe ratio declines too, although the magnitude of the decline is rather small. The distributional characteristics of excess returns are in general similar to those in Table 8, with large standard deviation, large spread between the minimum and the maximum, and even larger positive skewness and kurtosis. The relative frequency of positive returns versus negative returns is about twice to three times higher than those in Table 8 , indicating a much higher probability of earning positive excess returns than the previous case. For example, the percentage of positive (negative) excess returns for DJIA is $87.5 \%$ (12.5\%).

[Insert Table 11 about here]

Table 12 reports the summary statistics of excess returns with the cut-off point of one standard deviation. Again, we find excess returns are large but volatile, and positively skewed. The magnitudes of excess returns, Sharpe ratio and the ratio of positive versus negative returns are in between the previous two cases. 
[Insert Table 12 about here]

Overall, we find large excess returns and similar distribution characteristics in alternative trading strategies. The choice of cut-off points considered in this paper does not change qualitatively the profitability of the trading strategy.

\subsection{Limits to Arbitrage}

The large excess returns documented in the previous section do not necessarily translate into arbitrage opportunities. Existing literature shows that there are various limits to arbitrage to prevent sophisticated investors from eliminating the mispricing. We now consider how limits to arbitrage affect the profitability of our trading strategy.

\section{Transaction Cost}

Transaction costs have been considered as explanation for a number of financial anomalies, such as the "January effect" (Bhardwaj and Brooks (1992)), momentum profits (Lesmond et al. (2004)) and the "accrual anomaly" (Mashruwala et al. (2006)). To illustrate the role of transaction costs, we incrementally increase the one-way transaction cost from 0 to $0.2 \% .^{9}$ Panel B to Panel D in Table 8 report the excess returns based on these costs for the case of 75th percentile cut-off point. Not surprisingly, the profitability of the trading strategy declines with increment of transaction costs. Still, average excess returns remain positive even after taking these trading costs into account. DJIA has the smallest annualized excess returns of $14.04 \%$ among the three stock indices after $0.2 \%$ of transaction costs have been accounted. Our trading strategy delivers the best results for the Nasdaq index, with an annualized excess return of $20.28 \%$. The is not surprising since we assume the same transaction costs across different markets while in reality the transaction costs for trading the DJIA and S\&P 500 equities should be lower than trading those in the relatively less liquid index such as Nasdaq.

The excess returns after transaction costs are lower for the alternative trading strategies. When the cut-off point at 90th percentile is assumed, the annualized excess returns after $0.2 \%$ one way transaction costs are 9.36\% for DJIA and $12.48 \%$ for Nasdaq (Panel D of Table 11). The results with a cut-off point at one standard deviation are similar.

Overall, we find that transaction costs cannot fully explain the profitability of the trading strategy. Taking them into account does reduce the excess returns, but the excess returns after transaction costs remain large.

\footnotetext{
${ }^{9}$ The 14th annual survey of trading costs, conducted for Institutional Investor by New York-based Elkins/McSherry (a subsidiary of Boston's State Street Corp.) reports overall average cost of of 19.63 basis points for equity trading in the U.S. between July 2009 and June 2010 .
} 


\section{Liquidity Risk}

Another possible explanation for the excess returns is the liquidity risk. To see this, we report the breakdown of excess returns conditional on liquidity. We use the Pastor-Stambaugh liquidity factors as a measure of market illiquidity risk in the U.S. equity markets..$^{10}$ The data are available between 08/1962 and $12 / 2011$ at the monthly frequency. We consider both the level of aggregate liquidity and the innovation in aggregate liquidity.

Table 13 reports the average excess returns in different quartiles of liquidity factors. When there is no transaction cost, we can see an almost monotonic decline of excess returns with the increase of liquidity regardless which liquidity factor is considered. The extremely high positive returns occur when the level of aggregate liquidity is lowest. For DJIA, it corresponds to an annualized excess return of $43.16 \%$. When the liquidity is in its highest quartile, the annualized excess return is $3.6 \%$. We find stronger results for S\&P 500 and Nasdaq. Increment of transaction costs does not affect the excess return-liquidity pattern. These results show a strong negative relationship between excess returns and liquidity risk, consistent with the idea that excess returns are the compensation for bearing the liquidity risk.

[Insert Table 13 about here]

To highlight the role of liquidity risk on excess returns further, we regress excess returns on two lagged (by one-month) liquidity factors. We use lagged liquidity factors to avoid endogeneity issues. Table 14 reports the results when the excess returns are computed from a cut-off point of 75 th percentile. It shows that both liquidity factors have significantly negative coefficients which are mostly significant at the $10 \%$ level. Although the statistical significance is not strong, the economic significance of these coefficients is large, echoing the results in Table 13. Results for excess returns based on alternative trading strategies are similar. Although not reported, inclusion of additional regressors such as moments of past returns and macroeconomic variables does not affect the relationship between the excess returns and the liquidity factors. ${ }^{11}$

[Insert Table 14 about here]

\footnotetext{
${ }^{10}$ We thank Lubos Pastor and Robert F. Stambaugh for making their liquidity factor data available through their web page (see http://faculty.chicagobooth.edu/lubos.pastor/research/).

${ }^{11}$ Results are available from the authors upon request.
} 


\section{Time Variation of Excess Returns}

Table 8 shows that excess returns are volatile and the spreads between the minimum and the maximum are large. This certainly resembles one additional risk of the trading strategy. To highlight this risk, we plot the time path of excess returns in two additional figures.

Consider an investor who follows this strategy that invests on the DJIA index from time $t$ until the end of the sample period. Figure 1 and Figure 2 plot the corresponding average weekly excess returns and Sharpe Ratio for this investor at time $t$. The graph ends on 8th April, 2011 (52 weeks to the end of the sample period) due to insufficient remaining data to calculate average excess returns and Sharpe ratio. We find substantial variations in both average excess returns and Sharpe ratio, depending on when the investor starts to follow the strategy. Implementing the strategy before the 2008 leads to large average excess returns. There is a sharp decline immediately after the year 2008, leading to much lower average excess returns and Sharpe ratio. At the end of the sample period (roughly from year 2011), the average excess returns and Sharpe ratio soar again. Higher transaction costs are more likely to induce investors to earn negative excess returns and lower Sharpe ratio. Despite this, we note that the average excess returns and Sharpe ratio are always positive, independent from the entrant time.

[Insert Figure 1 about here]

[Insert Figure 2 about here]

Alternatively, we consider an investor who has an investment horizon of one year, and compute his average excess returns for a fixed rolling window of one year. Figure 3 and Figure 4 show the performance at time $t$ of our trading strategy from that time over a year. Again we observe substantial time variation in both excess returns and Sharpe ratio. For some periods the investor earns negative excess returns, while in other periods the excess returns are positive and large (around year 2008).

[Insert Figure 3 about here]

[Insert Figure 4 about here] 
In summary, transaction costs, liquidity risk and strong time variation in the excess returns impose strong limits to arbitrage.

\subsection{Trading ETFs and Futures Contracts}

It might appear unclear what "buying/selling" an index means. We therefore examine the corresponding Exchange Traded Funds (ETFs) and the index future contracts. Data on ETFs are downloaded from Bloomberg while the settlement price of index future contracts are obtained from Datastream.

Applying the Trading Strategy to ETFs

By investing an ETF that tracks an index, an investor can achieve the diversification of an index fund as well as the ability to sell short. ETFs can be traded like stocks, and the transaction cost is usually low. We adjust our simple trading strategy to sell an ETF when SVI is high and to buy and hold it otherwise. Unfortunately, the data on ETFs which track the Nasdaq start only from 2011. Therefore we restrict our attention to two ETFs: one tracks DJIA ("DIA US Equity") and the other tracks S\&P 500 ("SPY US Equity"). Table 15 shows that the results of trading ETFs are similar to those of "trading" the index itself in Table 8.

[Insert Table 15 about here]

\section{Applying the Trading Strategy to Index Futures}

As an additional robustness check, we examine the performance of our trading strategy by applying it to the index futures. Transaction costs are lower in trading the futures contracts. In addition, taking short positions in the futures contract would not be a problem. Table 16 shows the performance of the trading strategy when it is applied to the price of index futures contracts at the cutoff point of $75 \%$. We find very similar results to those in Table 8.

[Insert Table 16 about here]

\section{Conclusion}

We construct a measure of individual investors' speculative demand for stocks from their online queries on penny stocks provided by SVI. We examine how it affects the return dynamics of U.S. stock indices. 
We find that contemporaneous returns increase with SVI. In addition, higher SVI causes lower near future returns, while recent high past returns weakly cause lower SVI. We also find that the influence of speculative demand on returns is more pronounced for Nasdaq than DJIA and S\&P 500.

Based on the in-sample results, we build a simple trading strategy that sells a stock index when SVI is high and buys and holds the stock index otherwise. It generates annual excess returns of up to $20 \%$ over the buy-and-hold strategy. When applying the trading strategy to the corresponding ETFs and index futures, we find similar results. Transaction costs and liquidity risk can partially explain the excess returns. Strong time variation of the excess returns imposes additional limits to arbitrage. 


\section{Tables and Figures}

Table 1. Summary Statistics of Attention Variables

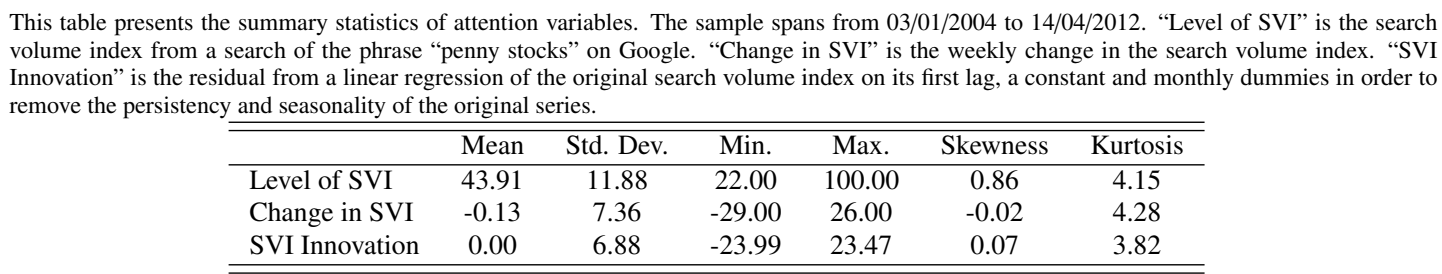


Table 2. Summary Statistics of Weekly Returns

This table presents the summary statistics of weekly returns of U.S. stock market indices. The sample spans from 03/01/2004 to 14/04/2012.

\begin{tabular}{l|cccccc}
\hline \hline & Mean & Std. Dev. & Min. & Max. & Skewness & Kurtosis \\
\hline DJIA & 0.05 & 2.59 & -20.03 & 10.70 & -0.98 & 12.24 \\
S\&P 500 & 0.05 & 2.77 & -20.08 & 11.36 & -0.91 & 10.96 \\
Nasdaq & 0.09 & 3.04 & -16.60 & 10.37 & -0.58 & 6.19 \\
\hline \hline
\end{tabular}


Table 3. Returns in High and Low Search Interest in Penny Stocks Periods

This table presents the summary statistics of one week return (in percentage) during high and low search interest in Penny Stocks periods. High and
low speculative demand periods are the periods which are higher respectively lower than the median speculative demand periods. The sample period
is from 03/01/2004 to 14/04/2012.
\begin{tabular}{|c|ccc|ccc}
\hline & \multicolumn{3}{|c|}{ Change in SVI } & \multicolumn{3}{c}{ SVI Innovation } \\
\hline & DJIA & SP500 & Nasdaq & DJIA & SP500 & Nasdaq \\
\hline Low SVI & -0.23 & -0.25 & -0.27 & -0.30 & -0.29 & -0.30 \\
\hline High SVI & 0.32 & 0.34 & 0.45 & 0.35 & 0.35 & 0.43 \\
\hline
\end{tabular}


Table 4. Univariate Regression of Contemporaneous Returns on Search Interest in Penny Stocks

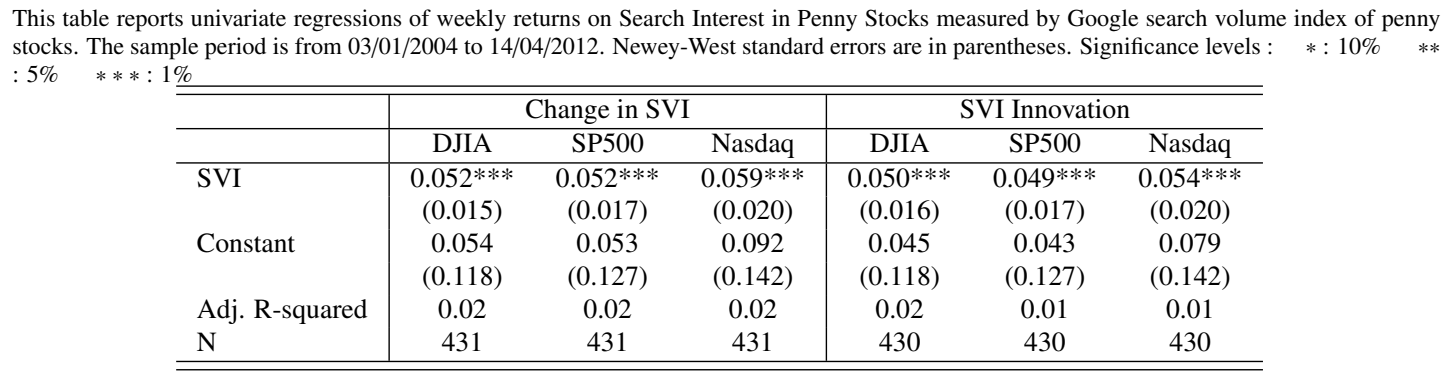


Table 5. Univariate GARCH Regression of Contemporaneous Returns and Search Interest in Penny Stocks

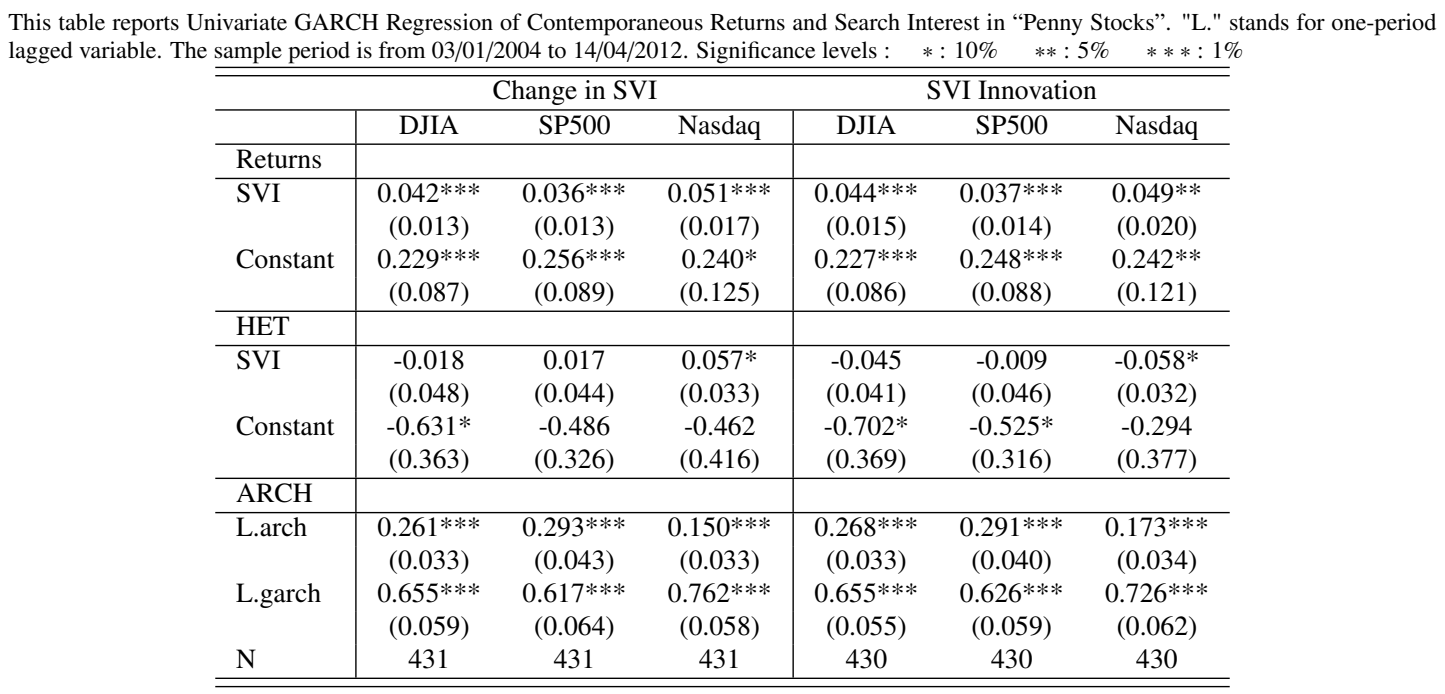


Table 6. Regression with Macro Variables

\begin{tabular}{|c|c|c|c|c|c|c|}
\hline \multirow[t]{3}{*}{ Significance levels : } & $* * *: 1 \%$ & & & & & \\
\hline & \multicolumn{3}{|c|}{ Change in SVI } & \multicolumn{3}{|c|}{ SVI Innovation } \\
\hline & DJIA & SP500 & Nasdaq & DJIA & SP500 & Nasdaq \\
\hline SVI & $\begin{array}{c}0.057 * * * \\
(0.015)\end{array}$ & $\begin{array}{c}0.057 * * * \\
(0.016)\end{array}$ & $\begin{array}{c}0.066^{* * *} \\
(0.019)\end{array}$ & $\begin{array}{c}0.051^{* * *} \\
(0.016)\end{array}$ & $\begin{array}{c}0.051^{* * * *} \\
(0.018)\end{array}$ & $\begin{array}{c}0.056^{\text {**** }} \\
(0.020)\end{array}$ \\
\hline L.retmean_30 & $\begin{array}{l}-1.002 \\
(1.042)\end{array}$ & $\begin{array}{c}-0.929 \\
(1.098)\end{array}$ & $\begin{array}{l}-0.380 \\
(0.998)\end{array}$ & $\begin{array}{l}-1.064 \\
(1.050)\end{array}$ & $\begin{array}{l}-0.980 \\
(1.110)\end{array}$ & $\begin{array}{l}-0.424 \\
(1.013)\end{array}$ \\
\hline L.retvar_30 & $\begin{array}{l}-0.084 \\
(0.080)\end{array}$ & $\begin{array}{l}-0.099 \\
(0.080)\end{array}$ & $\begin{array}{l}-0.106 \\
(0.088)\end{array}$ & $\begin{array}{l}-0.087 \\
(0.081)\end{array}$ & $\begin{array}{l}-0.102 \\
(0.080)\end{array}$ & $\begin{array}{l}-0.109 \\
(0.088)\end{array}$ \\
\hline L.retskew_30 & $\begin{array}{l}0.370 * \\
(0.208)\end{array}$ & $\begin{array}{c}0.613 * * \\
(0.240)\end{array}$ & $\begin{array}{l}0.524^{*} \\
(0.296)\end{array}$ & $\begin{array}{l}0.383^{*} \\
(0.210)\end{array}$ & $\begin{array}{c}0.626^{* *} * \\
(0.242)\end{array}$ & $\begin{array}{l}0.526^{*} \\
(0.297)\end{array}$ \\
\hline L.retkurt_30 & $\begin{array}{c}0.079 \\
(0.081)\end{array}$ & $\begin{array}{c}0.066 \\
(0.113)\end{array}$ & $\begin{array}{c}0.019 \\
(0.177)\end{array}$ & $\begin{array}{c}0.078 \\
(0.082)\end{array}$ & $\begin{array}{c}0.065 \\
(0.114)\end{array}$ & $\begin{array}{c}0.017 \\
(0.178)\end{array}$ \\
\hline L4.interest_rate & $\begin{array}{l}-0.004 \\
(0.058)\end{array}$ & $\begin{array}{l}-0.043 \\
(0.062)\end{array}$ & $\begin{array}{l}-0.067 \\
(0.072)\end{array}$ & $\begin{array}{l}-0.003 \\
(0.058)\end{array}$ & $\begin{array}{l}-0.043 \\
(0.062)\end{array}$ & $\begin{array}{l}-0.068 \\
(0.072)\end{array}$ \\
\hline L4.CCI_d & $\begin{array}{c}0.002 \\
(0.040)\end{array}$ & $\begin{array}{c}0.006 \\
(0.042)\end{array}$ & $\begin{array}{l}-0.003 \\
(0.043)\end{array}$ & $\begin{array}{c}0.003 \\
(0.040)\end{array}$ & $\begin{array}{c}0.007 \\
(0.042)\end{array}$ & $\begin{array}{l}-0.002 \\
(0.043)\end{array}$ \\
\hline L4.Industrial_Producation_d & $\begin{array}{c}0.352 \\
(0.544)\end{array}$ & $\begin{array}{c}0.435 \\
(0.657)\end{array}$ & $\begin{array}{c}0.435 \\
(0.789)\end{array}$ & $\begin{array}{c}0.338 \\
(0.541)\end{array}$ & $\begin{array}{c}0.420 \\
(0.654)\end{array}$ & $\begin{array}{c}0.416 \\
(0.785)\end{array}$ \\
\hline L4.CPI_d & $\begin{array}{l}-1.058 \\
(1.713)\end{array}$ & $\begin{array}{l}-1.009 \\
(1.876)\end{array}$ & $\begin{array}{l}-0.491 \\
(2.097)\end{array}$ & $\begin{array}{l}-1.142 \\
(1.728)\end{array}$ & $\begin{array}{l}-1.091 \\
(1.886)\end{array}$ & $\begin{array}{l}-0.575 \\
(2.109)\end{array}$ \\
\hline L4.M2_d & $\begin{array}{c}1.170 \\
(0.834)\end{array}$ & $\begin{array}{c}1.316 \\
(0.892)\end{array}$ & $\begin{array}{l}1.435 \\
(0.895)\end{array}$ & $\begin{array}{c}1.227 \\
(0.846)\end{array}$ & $\begin{array}{c}1.373 \\
(0.905)\end{array}$ & $\begin{array}{c}1.501 \\
(0.911)\end{array}$ \\
\hline Constant & $\begin{array}{l}-0.079 \\
(0.357)\end{array}$ & $\begin{array}{c}0.112 \\
(0.423)\end{array}$ & $\begin{array}{c}0.361 \\
(0.575)\end{array}$ & $\begin{array}{l}-0.073 \\
(0.359)\end{array}$ & $\begin{array}{c}0.118 \\
(0.425)\end{array}$ & $\begin{array}{c}0.368 \\
(0.579)\end{array}$ \\
\hline Adj. R-squared & 0.03 & 0.04 & 0.03 & 0.02 & 0.03 & 0.03 \\
\hline $\mathrm{N}$ & 420 & 420 & 420 & 420 & 420 & 420 \\
\hline
\end{tabular}


Table 7. VAR of Returns and Search Interest in Penny Stocks

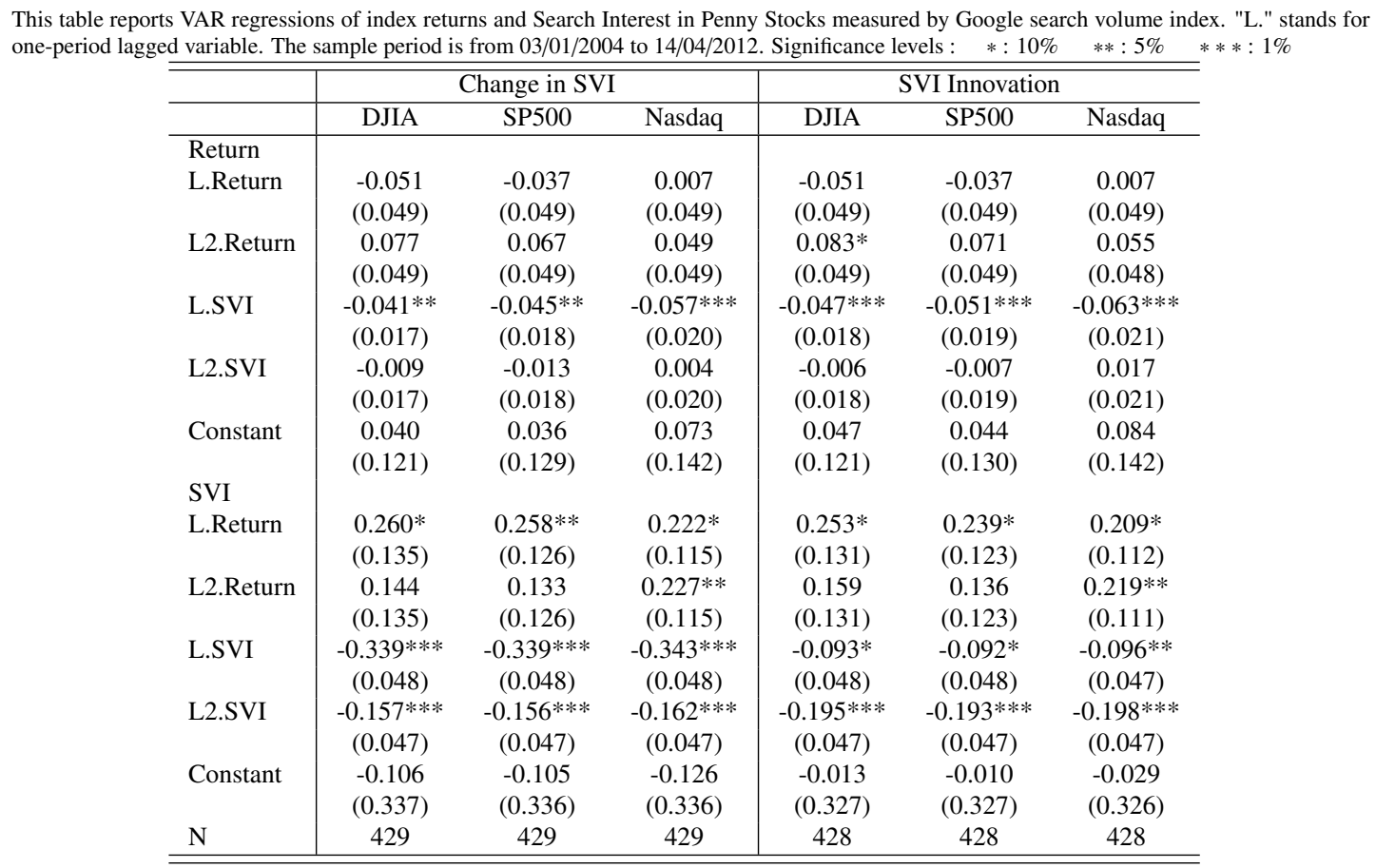


Table 8 .

Summary Statistics of Excess Returns over Buy-and-hold Strategy

\begin{tabular}{|c|c|c|c|c|c|c|c|c|c|}
\hline & Mean & Std. Dev. & Minimum & Maximum & Skewness & Kurtosis & \# of Trades & Pos/Neg & Sharpe Ratio \\
\hline & \multicolumn{9}{|c|}{ Panel A: Zero Transaction Cost } \\
\hline DJIA & 0.34 & 2.44 & -7.18 & 25.02 & 5.14 & 42.51 & 142 & 2.31 & 0.14 \\
\hline S\&P 500 & 0.42 & 2.76 & -8.01 & 29.82 & 5.73 & 48.62 & 142 & 2.69 & 0.15 \\
\hline Nasdaq & 0.46 & 3.03 & -8.74 & 32.32 & 5.28 & 44.38 & 142 & 2.84 & 0.15 \\
\hline & \multicolumn{9}{|c|}{ Panel B: One Way Transaction Cost: $0.05 \%$} \\
\hline DJIA & 0.32 & 2.43 & -7.28 & 24.92 & 5.12 & 42.59 & 142 & 2.31 & 0.13 \\
\hline S\&P 500 & 0.41 & 2.75 & -8.11 & 29.72 & 5.72 & 48.81 & 142 & 2.69 & 0.15 \\
\hline Nasdaq & 0.45 & 3.02 & -8.84 & 32.22 & 5.26 & 44.53 & 142 & 2.84 & 0.15 \\
\hline & \multicolumn{9}{|c|}{ Panel C: One Way Transaction Cost: $0.1 \%$} \\
\hline DJIA & 0.30 & 2.42 & -7.38 & 24.82 & 5.08 & 42.65 & 142 & 2.31 & 0.13 \\
\hline S\&P 500 & 0.39 & 2.74 & -8.21 & 29.62 & 5.70 & 48.98 & 142 & 2.56 & 0.14 \\
\hline Nasdaq & 0.43 & 3.00 & -8.94 & 32.12 & 5.25 & 44.67 & 142 & 2.69 & 0.14 \\
\hline & \multicolumn{9}{|c|}{ Panel D: One Way Transaction Cost: $0.2 \%$} \\
\hline DJIA & 0.27 & 2.40 & -7.58 & 24.62 & 5.00 & 42.66 & 142 & 2.10 & 0.11 \\
\hline S\&P 500 & 0.35 & 2.72 & -8.41 & 29.42 & 5.67 & 49.23 & 142 & 2.20 & 0.13 \\
\hline Nasdaq & 0.39 & 2.98 & -9.14 & 31.92 & 5.20 & 44.88 & 142 & 2.43 & 0.13 \\
\hline
\end{tabular}




\section{Table 9. Excess Returns Regressions}

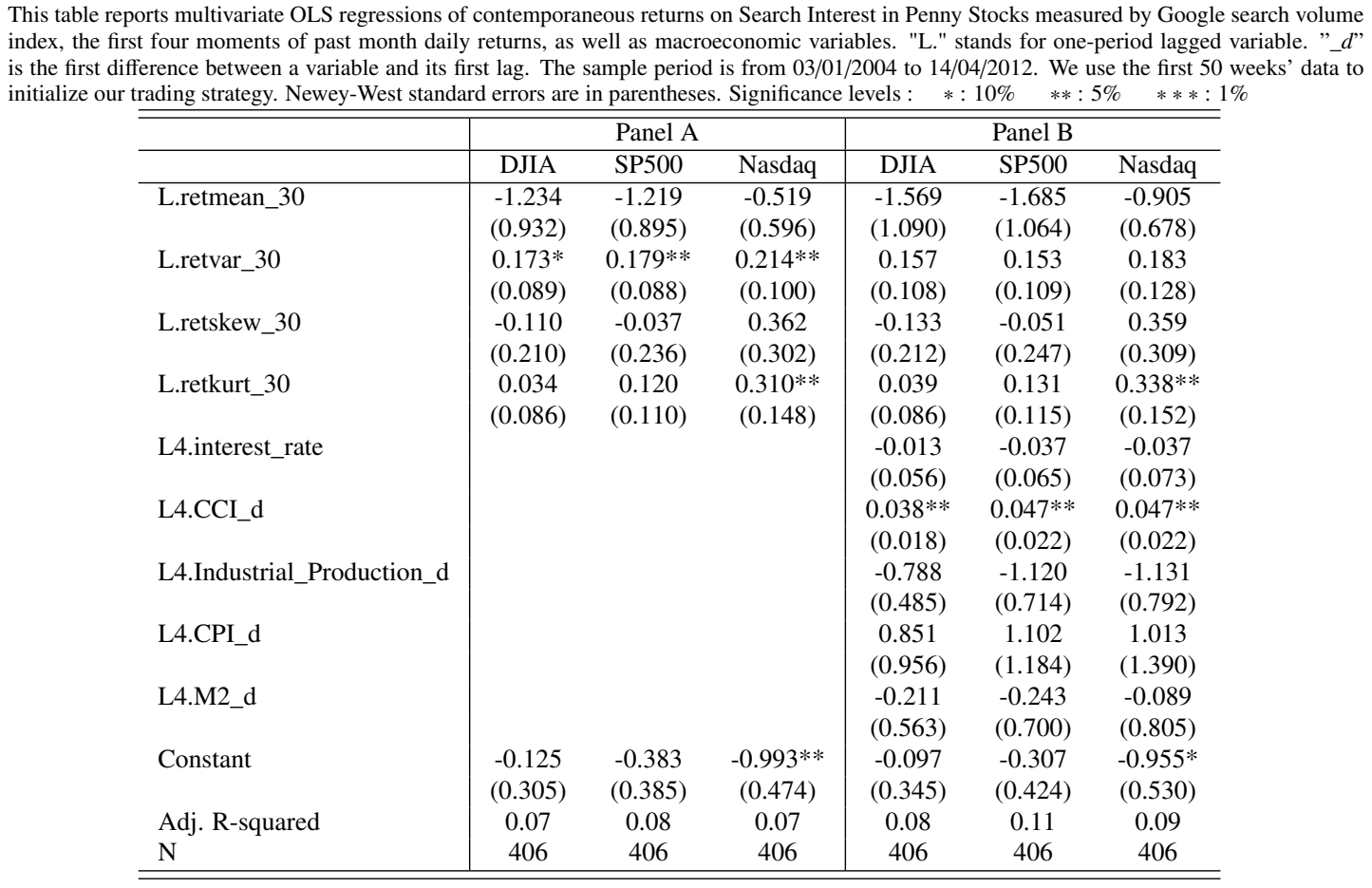


Table 10. Effect of Outliers on Excess Returns

\begin{tabular}{|c|c|c|c|c|c|c|c|}
\hline & Mean & Std. Dev. & Min. & Max. & Skewness & Kurtosis & Sharpe Ratio \\
\hline & \multicolumn{7}{|c|}{ Panel A: Zero Transaction Cost } \\
\hline DJIA & 0.23 & 1.60 & -4.36 & 11.25 & 3.76 & 23.74 & 0.14 \\
\hline S\&P 500 & 0.28 & 1.72 & -3.68 & 12.73 & 4.24 & 26.08 & 0.16 \\
\hline Nasdaq & 0.32 & 1.92 & -5.34 & 14.92 & 3.86 & 24.09 & 0.17 \\
\hline & \multicolumn{7}{|c|}{ Panel B: One Way Transaction Cost: $0.05 \%$} \\
\hline DJIA & 0.21 & 1.59 & -4.46 & 11.15 & 3.69 & 23.65 & 0.13 \\
\hline S\&P 500 & 0.26 & 1.70 & -3.78 & 12.63 & 4.19 & 26.07 & 0.16 \\
\hline Nasdaq & 0.30 & 1.91 & -5.44 & 14.82 & 3.81 & 24.11 & 0.16 \\
\hline & \multicolumn{7}{|c|}{ Panel C: One Way Transaction Cost: $0.1 \%$} \\
\hline DJIA & 0.20 & 1.58 & -4.56 & 11.05 & 3.61 & 23.52 & 0.12 \\
\hline S\&P 500 & 0.26 & 1.68 & -3.87 & 12.53 & 4.25 & 26.56 & 0.15 \\
\hline Nasdaq & 0.29 & 1.90 & -5.54 & 14.72 & 3.76 & 24.10 & 0.15 \\
\hline & \multicolumn{7}{|c|}{ Panel D: One Way Transaction Cost: $0.2 \%$} \\
\hline DJIA & 0.14 & 1.47 & -4.76 & 10.60 & 3.21 & 22.86 & 0.09 \\
\hline S\&P 500 & 0.19 & 1.55 & -4.08 & 11.06 & 3.83 & 25.24 & 0.12 \\
\hline Nasdaq & 0.26 & 1.87 & -5.74 & 14.52 & 3.64 & 24.02 & 0.14 \\
\hline
\end{tabular}


Table 11. Summary Statistics of Excess Returns (Percentile)

\begin{tabular}{|c|c|c|c|c|c|c|c|c|c|}
\hline & Mean & Std. Dev. & Minimum & Maximum & Skewness & Kurtosis & \# of Trades & Pos/Neg & Sharpe Ratio \\
\hline & \multicolumn{9}{|c|}{ Panel A: Zero Transaction Cost } \\
\hline DJIA & 0.21 & 1.73 & -3.25 & 25.02 & 9.95 & 122.20 & 46 & 7.00 & 0.12 \\
\hline S\&P 500 & 0.25 & 2.03 & -3.67 & 29.82 & 10.41 & 130.47 & 46 & 8.60 & 0.13 \\
\hline Nasdaq & 0.26 & 2.19 & -3.48 & 32.32 & 10.67 & 135.47 & 46 & 7.00 & 0.12 \\
\hline & \multicolumn{9}{|c|}{ Panel B: One Way Transaction Cost: $0.05 \%$} \\
\hline DJIA & 0.20 & 1.72 & -3.35 & 24.92 & 9.98 & 123.21 & 46 & 7.00 & 0.12 \\
\hline S\&P 500 & 0.25 & 2.02 & -3.77 & 29.72 & 10.45 & 131.56 & 46 & 8.60 & 0.12 \\
\hline Nasdaq & 0.26 & 2.18 & -3.58 & 32.22 & 10.71 & 136.40 & 46 & 7.00 & 0.12 \\
\hline & \multicolumn{9}{|c|}{ Panel C: One Way Transaction Cost: $0.1 \%$} \\
\hline DJIA & 0.20 & 1.71 & -3.45 & 24.82 & 10.01 & 124.17 & 46 & 7.00 & 0.11 \\
\hline S\&P 500 & 0.24 & 2.01 & -3.87 & 29.62 & 10.49 & 132.62 & 46 & 8.60 & 0.12 \\
\hline Nasdaq & 0.25 & 2.17 & -3.68 & 32.12 & 10.74 & 137.29 & 46 & 7.00 & 0.12 \\
\hline & \multicolumn{9}{|c|}{ Panel D: One Way Transaction Cost: $0.2 \%$} \\
\hline DJIA & 0.18 & 1.68 & -3.65 & 24.62 & 10.05 & 125.95 & 46 & 7.00 & 0.11 \\
\hline S\&P 500 & 0.23 & 1.99 & -4.07 & 29.42 & 10.57 & 134.66 & 46 & 5.00 & 0.12 \\
\hline Nasdaq & 0.24 & 2.15 & -3.88 & 31.92 & 10.80 & 138.99 & 46 & 7.00 & 0.11 \\
\hline
\end{tabular}


Table 12. Summary Statistics of Excess Returns (One Standard Deviation)

This table presents the summary statistics of the excess returns over the buy-and-hold strategy. The trading strategy sells a stock index at time $t$ when SVI is above one standard deviation of its historical values up to time $t$ and buys and holds the stock index otherwise. "Pos/Neg" is the relative frequency of positive returns versus negative returns. The sample period is from 03/01/2004 to 14/04/2012. We use the first 50 weeks' data to initialize our trading strategy.

\begin{tabular}{|c|c|c|c|c|c|c|c|c|c|}
\hline & Mean & Std. Dev. & Minimum & Maximum & Skewness & Kurtosis & \# of Trades & Pos/Neg & Sharpe Ratio \\
\hline & \multicolumn{9}{|c|}{ Panel A: Zero Transaction Cost } \\
\hline DJIA & 0.25 & 1.82 & -3.25 & 25.02 & 8.79 & 100.36 & 60 & 5.88 & 0.14 \\
\hline S\&P 500 & 0.30 & 2.17 & -3.67 & 29.82 & 9.00 & 102.87 & 60 & 5.88 & 0.14 \\
\hline \multirow[t]{2}{*}{ Nasdaq } & 0.31 & 2.38 & -4.72 & 32.32 & 8.97 & 101.51 & 60 & 5.11 & 0.13 \\
\hline & \multicolumn{9}{|c|}{ Panel B: One Way Transaction Cost: $0.05 \%$} \\
\hline DJIA & 0.24 & 1.80 & -3.35 & 24.92 & 8.83 & 101.37 & 60 & 5.88 & 0.13 \\
\hline S\&P 500 & 0.29 & 2.15 & -3.77 & 29.72 & 9.03 & 103.77 & 60 & 5.88 & 0.14 \\
\hline \multirow[t]{2}{*}{ Nasdaq } & 0.30 & 2.36 & -4.82 & 32.22 & 8.99 & 102.16 & 60 & 5.11 & 0.13 \\
\hline & \multicolumn{9}{|c|}{ Panel C: One Way Transaction Cost: $0.1 \%$} \\
\hline DJIA & 0.23 & 1.79 & -3.45 & 24.82 & 8.86 & 102.34 & 60 & 5.88 & 0.13 \\
\hline S\&P 500 & 0.29 & 2.14 & -3.87 & 29.62 & 9.06 & 104.65 & 60 & 5.88 & 0.13 \\
\hline \multirow[t]{2}{*}{ Nasdaq } & 0.29 & 2.35 & -4.92 & 32.12 & 9.01 & 102.79 & 60 & 5.11 & 0.13 \\
\hline & \multicolumn{9}{|c|}{ Panel D: One Way Transaction Cost: $0.2 \%$} \\
\hline DJIA & 0.22 & 1.77 & -3.65 & 24.62 & 8.90 & 104.15 & 60 & 5.88 & 0.12 \\
\hline S\&P 500 & 0.27 & 2.12 & -4.07 & 29.42 & 9.12 & 106.30 & 60 & 4.00 & 0.13 \\
\hline Nasdaq & 0.28 & 2.33 & -5.12 & 31.92 & 9.04 & 103.95 & 60 & 5.11 & 0.12 \\
\hline
\end{tabular}


Figure 1. Excess Returns to Trading Strategies

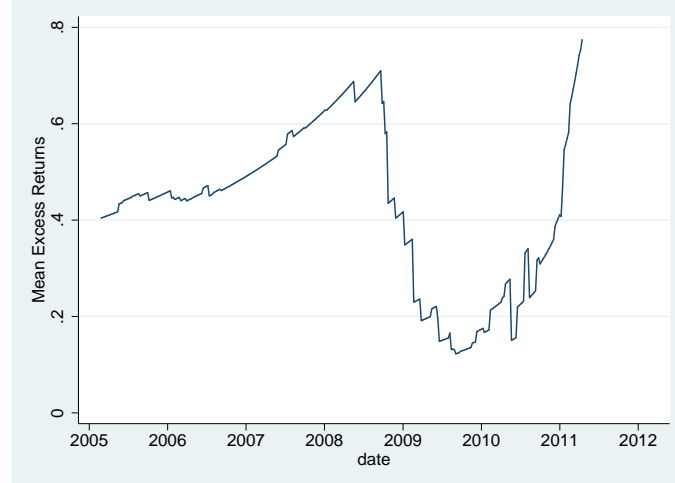

(a) No Transaction Cost

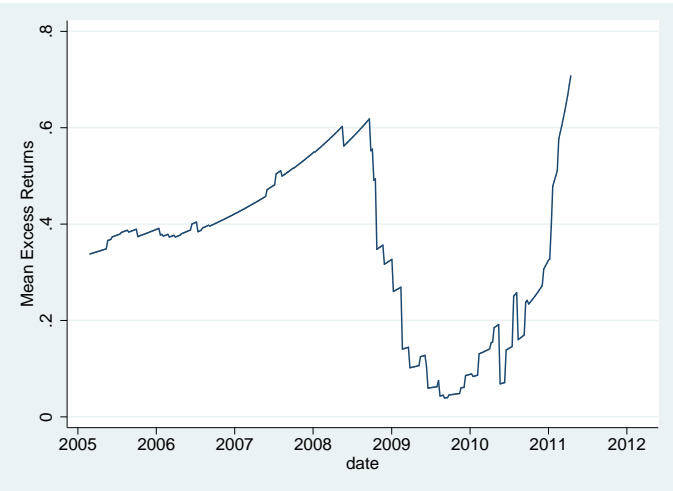

(b) One way transaction cost: $0.2 \%$

This figure shows the average weekly excess returns to trading strategies. Each point in the plot shows the average excess returns calculated from the excess returns from that time point till the end of the sample period. The sample period spans from 03/01/2004 to $14 / 04 / 2012$. We use the first 50 weeks' data to initialize our trading strategy. 
Figure 2. Sharpe Ratio of Excess Returns to Trading Strategies

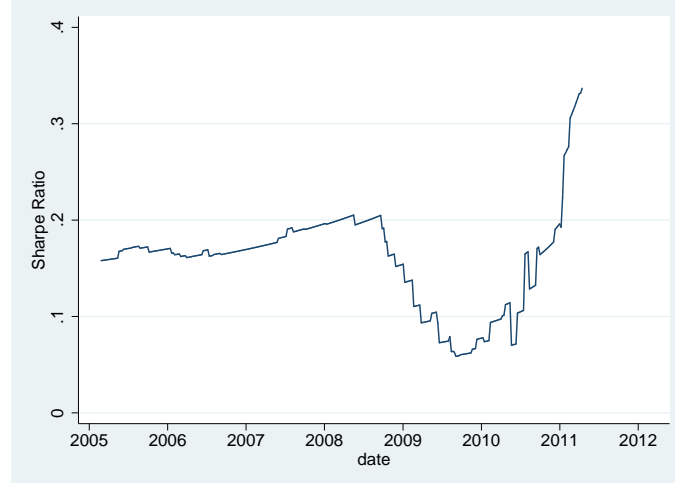

(a) No Transaction Cost

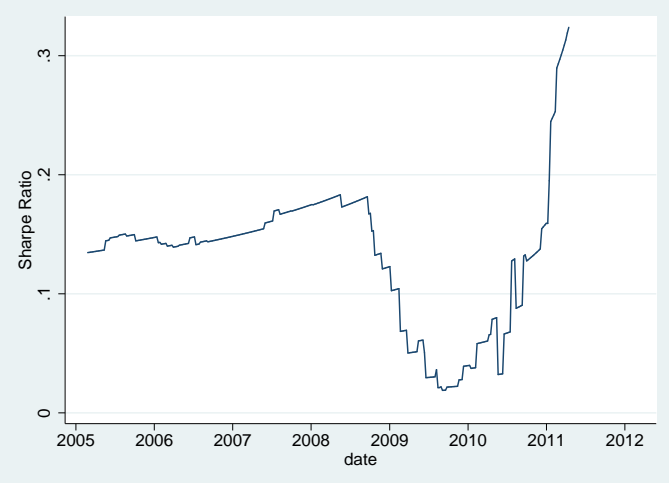

(b) One way transaction cost: $0.2 \%$

This figure shows the Sharpe ratio of weekly excess returns to trading strategies. Each point in the plot shows the Sharpe ratio calculated from the excess returns from that time point till the end of the sample period. The sample period spans from 03/01/2004 to 14/04/2012. We use the first 50 weeks' data to initialize our trading strategy. 
Figure 3. Excess Returns to Trading Strategies: Rolling Window

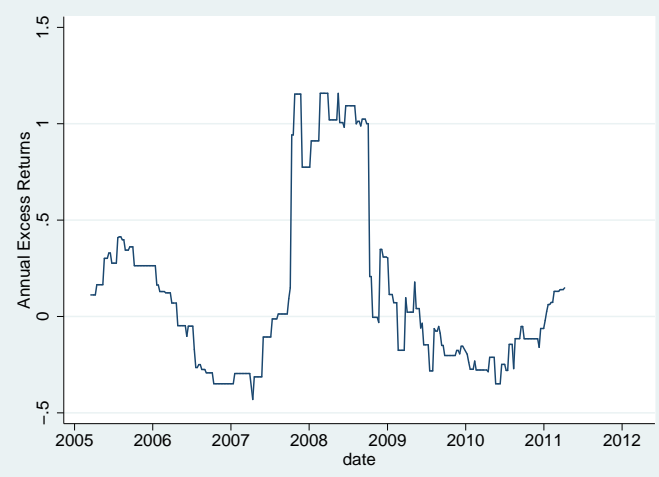

(a) DJIA

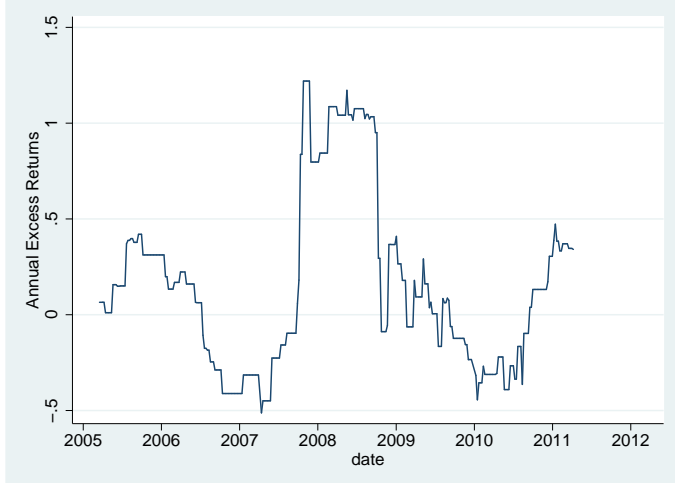

(b) NASDAQ

This figure shows the excess returns over the buy-and-hold strategy with one-way transaction cost of $0.2 \%$. Each point in the plot shows the average weekly returns (in percentage) in the next 50 weeks starting from that time point. The sample period is from $03 / 01 / 2004$ to $14 / 04 / 2012$. We use the first 50 weeks' data to initialize our trading strategy. 
Figure 4. Sharpe Ratio of Excess Returns to Trading Strategies: Rolling Window

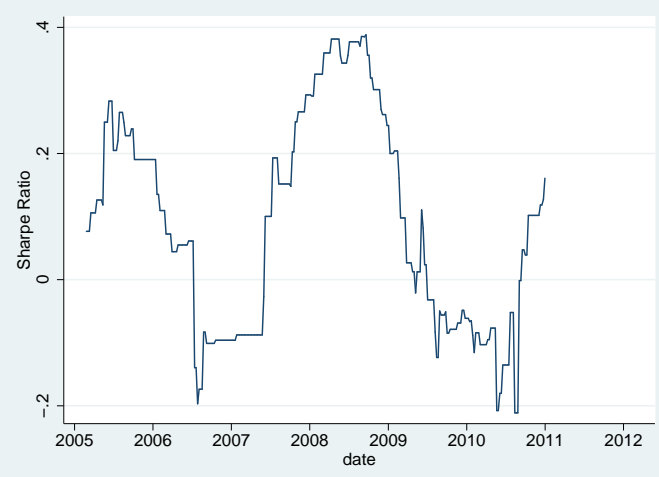

(a) DJIA

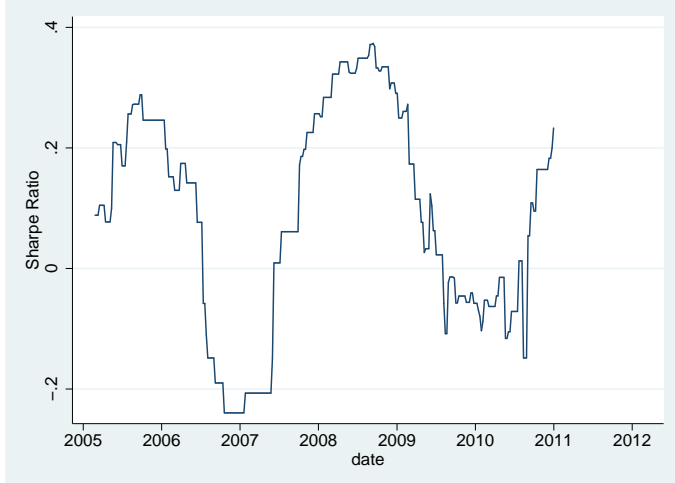

(b) NASDAQ

This figure shows the Sharpe ratio of excess returns over the buy-and-hold strategy with one-way transaction cost of $0.2 \%$. Each point in the plot shows the Sharpe ratio of weekly returns in the past 50 weeks up to that time point. The sample period is from 03/01/2004 to $14 / 04 / 2012$. We use the first 50 weeks' data to initialize our trading strategy. 
Table 13. Breakdown of Excess Returns Conditional on Liquidity

\begin{tabular}{|c|c|c|c|c|c|c|}
\hline & DJIA & SP500 & Nasdaq & DJIA & SP500 & Nasdaq \\
\hline Liquidity Quartile & & & & & & \\
\hline & \multicolumn{3}{|c|}{ Transaction Cost: $0 \%$} & \multicolumn{3}{|c|}{ Transaction Cost: $0.05 \%$} \\
\hline & \multicolumn{6}{|c|}{ Panel A: Liquidity Level } \\
\hline 1 & 0.83 & 0.99 & 0.91 & 0.82 & 0.97 & 0.89 \\
\hline 2 & 0.54 & 0.67 & 0.82 & 0.52 & 0.65 & 0.80 \\
\hline 3 & -0.09 & -0.02 & 0.05 & -0.12 & -0.04 & 0.03 \\
\hline 4 & 0.07 & 0.05 & 0.08 & 0.06 & 0.04 & 0.07 \\
\hline & \multicolumn{6}{|c|}{ Panel B: Liquidity Innovation } \\
\hline 1 & 0.90 & 1.03 & 1.04 & 0.89 & 1.01 & 1.02 \\
\hline 2 & 0.18 & 0.26 & 0.45 & 0.16 & 0.24 & 0.43 \\
\hline 3 & 0.39 & 0.45 & 0.47 & 0.37 & 0.43 & 0.45 \\
\hline 4 & -0.14 & -0.07 & -0.12 & -0.15 & -0.09 & -0.13 \\
\hline Liquidity Quartile & & & & & & \\
\hline & Tran & ction $\mathrm{Co}$ & $0.1 \%$ & Tran & ction $\mathrm{Co}$ & $0.2 \%$ \\
\hline & \multicolumn{6}{|c|}{ Panel C: Liquidity Level } \\
\hline 1 & 0.80 & 0.96 & 0.87 & 0.77 & 0.92 & 0.84 \\
\hline 2 & 0.50 & 0.63 & 0.78 & 0.46 & 0.59 & 0.74 \\
\hline 3 & -0.14 & -0.06 & 0.00 & -0.19 & -0.11 & -0.05 \\
\hline 4 & 0.05 & 0.02 & 0.06 & 0.03 & 0.00 & 0.04 \\
\hline & \multicolumn{6}{|c|}{ Panel D: Liquidity Innovation } \\
\hline 1 & 0.87 & 1.00 & 1.01 & 0.83 & 0.96 & 0.97 \\
\hline 2 & 0.14 & 0.23 & 0.41 & 0.10 & 0.19 & 0.37 \\
\hline 3 & 0.35 & 0.41 & 0.43 & 0.32 & 0.38 & 0.40 \\
\hline 4 & -0.17 & -0.10 & -0.15 & -0.20 & -0.14 & -0.19 \\
\hline
\end{tabular}


Table 14. Excess Returns Regressions: the Role of Liquidity

\begin{tabular}{|c|c|c|c|c|c|c|}
\hline & DJIA & SP500 & Nasdaq & $\overline{\text { DJIA }}$ & SP500 & Nasdaq \\
\hline L3.liquidity_innovation & $\begin{array}{c}-5.609 * * \\
(2.626)\end{array}$ & $\begin{array}{c}-6.304 * * \\
(3.053)\end{array}$ & $\begin{array}{l}-5.078^{*} \\
(2.827)\end{array}$ & & & \\
\hline L3.liquidity_level & & & & $\begin{array}{c}-5.182 * * \\
(2.524)\end{array}$ & $\begin{array}{l}-5.730^{*} \\
(2.969)\end{array}$ & $\begin{array}{c}-5.671 * \\
(3.115)\end{array}$ \\
\hline Constant & $\begin{array}{c}0.276 * * \\
(0.121)\end{array}$ & $\begin{array}{c}0.363 * * * \\
(0.135)\end{array}$ & $\begin{array}{c}0.401 * * * \\
(0.145)\end{array}$ & $\begin{array}{c}0.111 \\
(0.102)\end{array}$ & $\begin{array}{c}0.180 \\
(0.111)\end{array}$ & $\begin{array}{l}0.221^{*} \\
(0.130)\end{array}$ \\
\hline Adj. R-squared & 0.02 & 0.02 & 0.01 & 0.02 & 0.02 & 0.02 \\
\hline $\mathrm{N}$ & 406 & 406 & 406 & 406 & 406 & 406 \\
\hline
\end{tabular}


Table 15.

Summary Statistics of Excess Returns over Buy-and-hold Strategy: Exchange Traded Funds

\begin{tabular}{|c|c|c|c|c|c|c|c|c|}
\hline & Mean & Std. Dev. & Minimum & Maximum & Skewness & Kurtosis & Pos/Neg & Sharpe Ratio \\
\hline & \multicolumn{8}{|c|}{ Panel A: Zero Transaction Cost } \\
\hline DJIA & 0.33 & 2.55 & -9.10 & 30.07 & 5.29 & 56.00 & 1.89 & 0.13 \\
\hline \multirow[t]{2}{*}{ S\&P 500} & 0.37 & 2.79 & -9.71 & 32.60 & 5.63 & 56.91 & 2.38 & 0.13 \\
\hline & \multicolumn{8}{|c|}{ Panel B: One Way Transaction Cost: $0.05 \%$} \\
\hline DJIA & 0.31 & 2.54 & -9.20 & 29.97 & 5.25 & 56.23 & 1.79 & 0.12 \\
\hline \multirow[t]{2}{*}{ S\&P 500} & 0.36 & 2.78 & -9.81 & 32.50 & 5.61 & 57.13 & 2.12 & 0.13 \\
\hline & \multicolumn{8}{|c|}{ Panel C: One Way Transaction Cost: $0.1 \%$} \\
\hline DJIA & 0.29 & 2.53 & -9.30 & 29.87 & 5.22 & 56.41 & 1.61 & 0.11 \\
\hline \multirow[t]{2}{*}{ S\&P 500} & 0.34 & 2.77 & -9.91 & 32.40 & 5.58 & 57.31 & 2.00 & 0.12 \\
\hline & \multicolumn{8}{|c|}{ Panel D: One Way Transaction Cost: $0.2 \%$} \\
\hline DJIA & 0.25 & 2.51 & -9.50 & 29.67 & 5.14 & 56.65 & 1.53 & 0.10 \\
\hline S\&P 500 & 0.30 & 2.75 & -10.11 & 32.20 & 5.52 & 57.57 & 1.70 & 0.11 \\
\hline
\end{tabular}


Table 16.

Summary Statistics of Excess Returns over Buy-and-hold Strategy: Index Futures

This table presents the summary statistics of excess returns to the simple trading strategy over the buy-and-hold strategy based on index futures. "Pos/Neg" is the relative frequency of positive returns versus negative returns. The sample spans from 03/01/2004 to 14/04/2012. We use the first 50 weeks' data to initialize our trading strategy.

\begin{tabular}{|c|c|c|c|c|c|c|c|c|c|}
\hline & Mean & Std. Dev. & Minimum & Maximum & Skewness & Kurtosis & \# of Trades & Pos/Neg & Sharpe Ratio \\
\hline & \multicolumn{9}{|c|}{ Panel A: Zero Transaction Cost } \\
\hline DJIA & 0.32 & 2.50 & -7.76 & 30.21 & 6.06 & 61.85 & 142 & 2.34 & 0.13 \\
\hline S\&P 500 & 0.42 & 2.83 & -8.42 & 34.21 & 6.34 & 62.48 & 142 & 2.88 & 0.15 \\
\hline \multirow[t]{2}{*}{ Nasdaq } & 0.41 & 2.98 & -8.88 & 31.46 & 4.76 & 41.13 & 142 & 2.59 & 0.14 \\
\hline & \multicolumn{9}{|c|}{ Panel B: One Way Transaction Cost: $0.05 \%$} \\
\hline DJIA & 0.30 & 2.49 & -7.86 & 30.11 & 6.04 & 62.07 & 142 & 2.34 & 0.12 \\
\hline S\&P 500 & 0.40 & 2.82 & -8.52 & 34.11 & 6.33 & 62.80 & 142 & 2.88 & 0.14 \\
\hline \multirow[t]{2}{*}{ Nasdaq } & 0.39 & 2.97 & -8.98 & 31.36 & 4.74 & 41.22 & 142 & 2.59 & 0.13 \\
\hline & \multicolumn{9}{|c|}{ Panel C: One Way Transaction Cost: $0.1 \%$} \\
\hline DJIA & 0.28 & 2.48 & -7.96 & 30.01 & 6.01 & 62.24 & 142 & 2.23 & 0.11 \\
\hline S\&P 500 & 0.38 & 2.80 & -8.62 & 34.01 & 6.32 & 63.09 & 142 & 2.46 & 0.14 \\
\hline \multirow[t]{2}{*}{ Nasdaq } & 0.38 & 2.96 & -9.08 & 31.26 & 4.70 & 41.29 & 142 & 2.46 & 0.13 \\
\hline & \multicolumn{9}{|c|}{ Panel D: One Way Transaction Cost: $0.2 \%$} \\
\hline DJIA & 0.25 & 2.46 & -8.16 & 29.81 & 5.94 & 62.44 & 142 & 2.03 & 0.10 \\
\hline S\&P 500 & 0.35 & 2.78 & -8.82 & 33.81 & 6.30 & 63.56 & 142 & 2.23 & 0.13 \\
\hline Nasdaq & 0.34 & 2.94 & -9.28 & 31.06 & 4.63 & 41.37 & 142 & 2.46 & 0.12 \\
\hline
\end{tabular}




\section{References}

Aggarwal, R., Rivoli, P., 1990. Fads in the initial public offering market? Financial Management 19, 45-57.

Andrei, D., Hasler, M., 2011. Investors' attention and stock market volatility, Working paper, Swiss Finance Institute .

Baker, M., Wurgler, J., 2006. Investor sentiment and the cross-section of stock returns. The Journal of Finance 61, 1645-1680.

Bank, M., Larch, M., Peter, G., 2011. Google search volume and its influence on liquidity and returns of German stocks. Financial Markets and Portfolio Management 25, 1-26.

Barber, B., Odean, T., 2008. All that glitters: The effect of attention and news on the buying behavior of individual and institutional investors. Review of Financial Studies 21, 785-818.

Beatty, R., Kadiyala, P., 2003. Impact of the Penny Stock Reform Act of 1990 on the initial public offering market. Journal of Law and Economics 46, 517-541.

Bhardwaj, R., Brooks, L., 1992. The January anomaly: Effects of low share price, transaction costs, and bid-ask bias. Journal of Finance 47, 553-575.

Bouraoui, T., 2011. The impact of stock spams on volatility. Applied Financial Economics 21, 969-977.

Bradley, D., Cooney Jr, J., Dolvin, S., Jordan, B., 2006. Penny stock IPOs. Financial Management 35, 5-29.

Cutler, D.M., Poterba, J.M., Summers, L.H., 1991. Speculative dynamics and the role of feedback traders. American Economic Review 80, 63-68.

Da, Z., Engelberg, J., Gao, P., 2010. In search of fundamentals, Working paper, University of Notre Dame and University of North Carolina at Chapel Hill .

Da, Z., Engelberg, J., Gao, P., 2012. In search of attention. Journal of Finance 66, 1461-1499.

De Long, J., Shleifer, A., Summers, L., Waldman, R., 1990. Noise traders risk in financial markets. Journal of Political Economy 98, 703-738.

Drake, M., Roulstone, D., Thornock, J., 2011. Investor information demand: Evidence from Google searches around earnings announcements. Journal of Accounting Research 50, 1001-1040.

Fisher, K., Statman, M., 2000. Investor sentiment and stock returns. Financial Analysts Journal 56, 16-23.

Hanke, M., Hauser, F., 2008. On the effects of stock spam e-mails. Journal of Financial Markets 11, 57-83. 
Hendershott, T., Menkveld, A., J., 2012. Price pressures. Working Pape, rUniversity of California-Barkeley.

Jegadeesh, N., Titman, S., 1993. Returns to buying winners and selling losers: Implications for stock market efficiency. Journal of Finance 48, 65-91.

Khandani, A.E., Lo, A.W., 2007. What happened to the quants in august 2007? Journal of Investment Management 5, 5-54.

Kyle, A., 1985. Continuous auctions and insider trading. Econometrica 53, 1315-1335.

Lesmond, D.A., Schill, M.J., Zhou, C., 2004. The illusory nature of momentum profits. Journal of Financial Economics 71, 349-380.

Levis, M., Liodakis, M., 2001. Contrarian strategies and investor expectations: the UK evidence. Financial Analysts Journal 57, 43-56.

Llorente, G., Michaely, R., Saar, G., Wang, J., 2002. Dynamic volume-return relation of individual stocks. Review of Financial Studies 15, 1005-1047.

Mashruwala, C., Rajgopal, S., Shevlin, T., 2006. Why is the accrual anomaly not arbitraged away? the role of idiosyncratic risk and transaction costs. Journal of Accounting and Economics 42, 3-33.

McLean, B., 2000. Making little cents the penny-stock boom is the latest indicator of speculative frenzy. Fortune-European Edition 141, 95-95.

Mondria, J., Wu, T., 2012. Asymmetric attention and stock returns, Working paper, University of Toronto .

Nagel, S., 2012. Evaporating liquidity. Review of Financial Studies 25, 2005-2039.

Peng, L., Xiong, W., 2006. Investor attention, overconfidence and category learning. Journal of Financial Economics 80, 563-602.

Rouwenhorst, K.G., 1998. International momentum strategies. Journal of Finance 53, 267-284.

Rouwenhorst, K.G., 1999. Local return factors and turnover in emerging stock markets. Journal of Finance $54,1439-1464$.

Sullivan, R., Timmermann, A., White, H., 1999. Data-snooping, technical trading rule performance, and the bootstrap. Journal of Finance 54, 1647-1691.

Vlastakis, N., Markellos, R., 2012. Information demand and stock market volatility. Journal of Banking \& Finance 36, 1808-1821.

Wang, J., 1994. A model of competitive stock trading volume. Journal of Political Economy 102, 127-68. 